\title{
KEBERLANJUTAN PROGRAM PENGEMBANGAN KEWIRAUSAHAAAN DI UNIVERSITAS MUHAMMADIYAH PALOPO
}

\author{
Hadi Pajarianto1), Imran Ukas'²), Imam Pribadi3) \\ 1)Program Studi PGPAUD, FKIP, Universitas Muhammadiyah Palopo, Palopo, Sulawesi Selatan, Indonesia \\ 2) Program Studi Manajemen, FEB, Universitas Muhammadiyah Palopo, Palopo, Sulawesi Selatan, Indonesia \\ ${ }^{3)}$ Program Studi Bimbingan Konseling, FKIP, Universitas Muhammadiyah Palopo, Palopo, Sulawesi Selatan, Indonesia
}

Corresponding author : Hadi Pajarianto

E-mail : hadipajarianto@umpalopo.ac.id

Diterima 12 Oktober 2021, Direvisi 26 November 2021, Disetujui 26 November 2021

\begin{abstract}
ABSTRAK
Perguruan tinggi dalam adalah bagian dari pusat kekuatan intelektual (intellectual power) yang diharapkan dapat memperkuat kegiatan kewirausahaan. Dengan terbitnya Peraturan Menteri Pendidikan dan Kebudayaan Nomor 3 tahun 2020, penguatan kewirausahaan kepada mahasiswa juga mendapatkan prioritas. Dalam delapan kegiatan Merdeka Belajar Kampus Merdeka (MBKM) salah satu bentuk kegiatannya adalah wirausaha mahasiswa. Tujuan PPK adalah memandu perguruan tinggi menyelenggarakan unit layanan kewirausahaan yang profesional, mandiri dan berkelanjutan, berwawasan knowledge based economy. Metode yang digunakan pengembangan kewirausahaan yaitu kompetisi bisnis, pelatihan, pendampingan, magang, dan pameran produk. Siklus kegiatan diklasifikasi menjadi tiga, Socio-Technopreneurship Awaraeness Campaign, agar PPK menjadi gerakan bersama di lingkungan perguruan tinggi, Capasity Building, yang dilaksanakan secara kordinatif, konsultatit, dan afirmatif dilakukan berkesinambungan dengan berbagai lembaga, dan Institutionalization adalah upaya pelembagaan kegiatan kewirausahaan di kampus sebagai upaya menciptakan jeringan dan mitra kerjasama. Hasil pelaksanaan PPK Universitas Muhammadiyah Palopo terlaksana sesuai dengan program dan target yang ingin dicapai. Selama 3 tahun pelaksanaan sejak 2019, 2020, dan 2021, telah melahirkan 15 wirausaha baru yang bergerak di bidang kuliner, souvenir, bookstore, dan jasa. Untuk menjamin keberlanjutan dan menentukan Entrepreneurship Priority, Universitas Muhammadiyah Palopo telah membentuk Unit Inkubasi dan Pengembangan Kewirausahaan (UIPK) yang bertugas untuk memfasilitasi mahasiswa dan alumni dalam pengembangan kewirausahaan. Luaran yang dihasilkan adalah jurnal pengabdian setiap tahun, hak cipta, poster, publikasi pada media masa cetak, dan buku ajar kewirausahaan.
\end{abstract}

Kata kunci: keberlanjutan; kewirausahaan; mahasiswa; alumni.

\begin{abstract}
Higher education is part of the core of intellectual power. It is anticipated to stimulate entrepreneurial activities. With the Minister of Education and Culture Regulation Number 3 of 2020, strengthening entrepreneurship for students is also a priority. One of the eight activities in Merdeka Belajar Kampus Merdeka (MBKM), is student entrepreneurship. With Knowledge-Based Economy Insight, the PPK aimed to guide universities in organizing professional, independent, and sustainable entrepreneurship service units. The approaches used in entrepreneurship advancement are business competition, training, mentoring, internships, and product exhibitions. The activity series is classified into three activities. First, Socio-Technopreneurship Awareness Campaign, so that KDP becomes a joint movement in the university context. Second, Capacity Building, which is carried out in a coordinated and consultative. The last is affirmative manner carried out continuously with various institutions, and Institutionalization is an attempt to institutionalize entrepreneurial activities on campus as an effort to create networks and cooperative partners. The PPK implementation result in the University of Muhammadiyah Palopo was carried out under the program and targeted realized. During the three years of implementation, fifteen new entrepreneurs have been born in the field of culinary, souvenirs, bookstores, and services. To ensure sustainability and determine Entrepreneurship Priority, the University of Muhammadiyah Palopo has established an Entrepreneurship Incubation and Development Unit (UIPK) to facilitate students and graduates in entrepreneurship development. The outputs produced are devotional journals every year, copyrights, posters, publications in print mass media, and entrepreneurship textbooks.
\end{abstract}

Keywords: sustainable; entrepreneurship; student; graduates 


\section{PENDAHULUAN}

Salah satu tugas perguruan tinggi adalah menyelaraskan pola pendidikan dengan kebutuhan dunia kerja dan mengurangi angka pengangguran. Mengutip data BPS, Astriani (2020) menguraikan jumlah pengangguran di Indonesia sejak tahun 2015 sampai dengan tahun 2018 masih tinggi tidak pernah di bawah angka 7 juta orang. Pengangguran tersebut diklasifikasi berdasarkan pendidikan yang ditamatkan menjadi enam kategori, SD, SMP, SMA, SMK, Diploma $1 / 1 / / I I$, dan Universitas (Astriani \& Nooraeni, 2020). Pada tahun 2018, lulusan diploma menduduki peringkat kedua pada tingkat pengangguran terbuka dengan persentase 7,92. Jika dicermati dari data, maka lulusan perguruan tinggi yang berada pada kategori penggangguran terbuka pada kurun waktu 3 tahun terakhir lebih besar dibandingkan dengan lulusan sekolah dasar. Hal ini penting menjadi perhatian perguruan tinggi untuk mengevaluasi seluruh proses pendidikannya agar selaras dengan kebutuhan dunia kerja. Idealnya, lulusan diploma dan sarjana yang diharapkan mampu membantu mengurangi angka pengangguran di Indonesia nyatanya justru turut menyumbangkan pengangguran dengan jumlah yang besar.

Perguruan tinggi dalam adalah bagian dari pusat kekuatan intelektual (intellectual power) yang diharapkan dapat memperkuat kegiatan kewirausahaan. Pemerintah melalui beberapa skema telah menyiapkan program dan pendanaan untuk mengakselerasi tujuan tersebut. Diantaranya melalui kegiatan Program Pengembangan Kewirausahaan (PPK). Misi program PPK adalah memandu perguruan tinggi menyelenggarakan unit layanan kewirausahaan yang profesional, mandiri dan berkelanjutan, berwawasan knowledge based economy. Program PPK harus mandiri dan operasionalnya berkelanjutan, sehingga PPK diberi peluang untuk mampu menjadi unit profit.

Selain itu, dengan terbitnya Peraturan Menteri Pendidikan dan Kebudayaan Nomor 3 tahun 2020, penguatan kewirausahaan kepada mahasiswa juga mendapatkan prioritas. Dalam delapan kegiatan Merdeka Belajar Kampus Merdeka (MBKM) salah satu bentuk kegiatannya adalah wirausaha mahasiswa. Mahasiswa adalah bagian dari generasi millienial Indonesia. Berdasarkan panduan Merdeka Belajar-Kampus Merdeka 2020 (Kemendikbud, 2020) yang mengutip riset dari IDN Research Institute tahun 2019, 69,1\% millennial di Indonesia memiliki minat untuk berwirausaha.

Dobon (Sundoro, 2014) mengemukakan bahwa motivasi kewirausahaan terdiri dari enam kelompok besar atau dimensi motivasi yaitu: (1) personal, yakni untuk mendapatkan penghargaan, keinginan untuk mendapatkan kemerdekaan dan keinginan untuk kekayaan; (2) keterkaitan antara motivasi dengan pengetahuan secara ilmiah, yang menjadi dorongan pengembangan karir dan peningkatan keterampilan (Etzkowitz, 1998); (4) keterkaitan motivasi dengan kesiapan sumber daya; (5) keterkaitan motivasi dengan inkubator organisasi; dan (6) keterkaitan motivasi dengan jejaring sosial.

Pada perguruan tinggi, mahasiswa biasanya mengalami hambatan untuk dapat mengatur waktu dengan baik, tepat, dan akurat karena pada prinsipnya, proses bisnis sangat berkaitan dengan interaksi dengan sistem lain yang berhubungan (Ismail, 2004). Mahasiswa dan dosen terkadang terlalu fokus dengan kegiatan di kelas, sehingga sulit mengatur waktu dengan kegiatan bisnis yang sedang dijalankan karena banyaknya tugas kuliah yang dibebankan kepada mahasiswa. Selain itu, mahasiswa yang setiap hari diberikan teori yang menuntut ideal, terkadang kurang percaya diri melakukan promosi terhadap produk bisnisnya, dan tidak mampu membangun jejaring dengan mitranya maupun khalayak yang memiliki keterkaitan dengan usahanya. Dalam dunia bisnis, kemitraan dan jejaring adalah aspek penting untuk memajukan usaha (Widyani, 2013).

Dari beberapa kegiatan kewirausahaan yang dilakukan di perguruan tinggi mampu mengasah jiwa wirausaha, meningkatkan soft skill dengan terlibat langsung di dunia kerja, dan berani membuka usaha serta cakap, terampil menumbuhkan sense of business sehingga tercipta wirausaha muda potensial berbasis ipteks (Yusuf \& Firman, 2019), dan kegiatan PPK yang dikolaborasi antara alumni dan mahasiswa mampu menghasilkan rata-rata wirausaha baru mandiri sebanyak 5 orang pertahun (Rufi et al., 2020). Bahkan ketika perguruan tinggi membekali alumninya dengan soft skill, diantaranya ketrampilan komputer dan Bahasa Inggris, pelatihan enterpreneurship, leadership dan ketenagakerjaan, maka akan menurunkan stres dalam mencari pekerjaan (Isnaini \& Lestari, 2015).

Kota Palopo sedang berkembang pesat menjadi kota jasa terkemuka di Sulawesi Selatan, memiliki Indeks Pembangunan Manusia 77,30 , dan pertumbuhan ekonomi melambat sebesar 6,75 pada tahun 2019. Di Palopo UMKM Ekonomi kreatif hadir dengan corak yang diyakini mampu meningkatkan perekonomian baik secara lokal maupun nasional. Bahkan di beberapa kampus berkembang socio-technopreneur di kalangan mahasiswa dan pendidiknya (Pajarianto et al., 
2019). Konsep ekonomi kreatif ternyata mampu memberikan kontribusi nyata terhadap perekonomian di beberapa negara. Data dari Kementerian Koperasi dan Usaha Kecil Menengah (KemenkopUKM) menunjukkan bahwa pada tahun 2018 terdapat 64.194 .057 UMKM yang ada di Indonesia (atau sekitar 99 persen dari total unit usaha) dan mempekerjakan 116.978.631 tenaga kerja, atau sekitar 97 persen dari total tenaga kerja di sektor ekonomi (Pakpahan, 2020).

Universitas Muhammadiyah Palopo merupakan penggabungan dari 3 perguruan tinggi Muhammadiyah di Kota Palopo, yakni; STKIP Muhammadiyah, STIE Muhammadiyah, dan AKBID Muhammadiyah, berdiri sejak tahun 2019 terdiri dari 3 fakultas dan 1 program pascasarjana. Pada tahun 2021 sebanyak 5 mahasiswa memenangkan PKM, dan pada tahun 2019, 2020, dan 2021 memenangkan Program Pengembangan Kewirausahaan.

Tagline Universitas Muhamamdiyah Palopo sebagai penjabaran dari visi dan misi adalah "Socio-Technopreneur, Unggul, dan Islami" yang diperkuat melalui kegiatan pendidikan dan pengajaran serta kegiatan lain yang bersifat non-akademik. Pada pendidikan dan pengajaran, telah disiapkan mata kuliah Socio-Technopreneur sebanyak 4 SKS, teori dan praktik, serta saat ini mengadopsi kewirausahaan sebagai salah satu bentuk dari 8 kegiatan MBKM. Program Pengembangan Kewirausahaan di Universitas Muhammadiyah Palopo dilaksanakan berdasarkan keunikan dan keunggulan produk yang dimiliki oleh tenant yang terdiri dari alumni dan mahasiswa.

Jenis produknya bervariasi, mulai dari kuliner, yakni: rumpun coffe, party planner BBT, queen kurma, gerobak kuliner dan peralatan outdoor, servise AC, bajabu bolu, rumah kue palopo, mbafood, sambal sabu-sabu kering, aplikasi gandeng , artmu, pengembangan madu trigona, Kuliner cepat saji, Edureptil, Edubooks Store, KriBoU, dan buket wisuda. Produk kewirausahaan mahasiswa Universitas Muhammadiyah Palopo sangat potensial untuk dijaga keberlanjutannya karena miliki nilai jual yang tinggi dengan kualitas yang dapat bersaing. Melalui kerjasama dengan semua pihak, kegiatan PPK yang telah diinisiasi dan dilaksanakan selama 3 tahun terakhir dapat menjadi modal utama untuk mempertahankan keberlanjutan kegiatan kewirausahaan ini, untuk mencapai visi socio-technopreneur.

\section{METODE \\ Tempat dan Waktu}

Kegiatan Program Pengembangan

Kewirausahaan dilaksanakan pada kampus Universitas Muhammadiyah Palopo, Jalan
Jenderal Sudirman Binturu Kota Palopo Sulawesi Selatan. PPK merupakan program kewirausahaaan multi tahun yang dilaksanakan sejak tahun 2019, 2020, dan 2021. Waktu pelaksanaan mulai bulan Februari sampai dengan bulan November.

\section{Khalayak Sasaran}

Sasaran dari Program PPK adalah mahasiswa Universitas Muhammadiyah Palopo, diutamakan yang memenangkan hibah PKM Kewirausahaan dari Dikti, dan atau alumni yang sedang menjalankan usaha. Dilihat dari sebaran prodinya didominasi oleh mahasiswa dan alumni FKIP dan FEBI. Tim pengusul melibatkan dosen lain yang memiliki kapasitas dalam kewirausahaan baik sebagai narasumber maupun instruktur dalam pelatihan. Jumlah tenant PPK tahun 2019, 2020, dan 2021 masing-masing 20 orang dalam setiap tahunnya dengan target setiap angkatan menghasilkan 5 orang wirausaha baru yang mandiri.

\section{Tahapan Pelaksanaan}

Metode pengabdian yang dilakukan yaitu (1) sosialisasi program PPK, (2) seleksi tenant, (3) pelatihan, pendampingan dan magang, (4) konsultasi bisnis; dan (4) penilaian tenant. Sosialisasi dilakukan melalui pertemuan baik dengan pimpinan, mahasiswa, dan alumni dengan memberikan penjelasan secara umum tentang program PPK. Seleksi tenant diikuti oleh 5 (lima) tenant yang telah merintis usaha, dan 15 (lima belas) tenant yang baru akan memulai.

Kegiatan dilakukan dengan tahapan; (1) Socio-Technopreneurship Awaraeness Campaign adalah solusi dan tahapan penting agar kewirausahaan menjadi gerakan bersama di lingkungan perguruan tinggi; (2) Capasity Building dengan pembinaan yang simultan terhadap tenant, sehingga memiliki pemahaman dan skill tentang manajemen usaha, manajemen produksi, dan diberikan skill untuk dapat menganalisis dan menyusun solusi atas berbagai hambatan usahanya. Sifatnya dapat kordinatif, konsultatit, dan afirmatif dilakukan berkesinambungan dengan berbagai lembaga; dan (3) Institutionalization adalah upaya pelembagaan kegiatan kewirausahaan di kampus sebagai upaya menciptakan jeringan dan mitra kerjasama antara Universitas Muhammadiyah Palopo. Penilaian kinerja bisnis dilakukan untuk mendapatkan gambaran dari keberhasilan program yang dilakukan.

\section{Indikator Keberhasilan}

Indikator keberhasilan kegiatan PPK sebagaimana ditargetkan dalam panduan 
adalah; (1) adanya wirausaha baru mandiri yang berbasis iptek, minimal 5 orang; (2) meningkatnya keterampilan manajemen usaha bagi masyarakat industri; (3) terlaksananya metode pelatihan kewirausahaan yang kompatibel dengan mahasiswa dan alumni sesuai dengan ciri khas bidang usaha masingmasing.

\section{Monitoring dan Evaluasi}

Metode evaluasi yang digunakan adalah dengan menyusun rubrik dari aspek kinerja, skor, bobot, dan nilai. Aspek yang dievaluasi dan dinilai adalah motivasi berusaha, kelembagaan dan SDM, teknis produksi, pengembangan pemasaran, pengelolaan keuangan, dan keberlanjutan usaha.

Tabel 1. Rubrik Penilaian Kinerja Tenant

\begin{tabular}{|c|c|c|c|c|}
\hline No & Aspek Kinerja & Skor & Bobot & Nilai \\
\hline 1. & Motivasi Usaha & & 20 & \\
\hline 2. & Kemampuan Kelembagaan dan SDM & & 10 & \\
\hline 3. & Kemampuan Teknis Produksi/Operasi & & 15 & \\
\hline 4. & Kemampuan Pengembangan Pasar & & 20 & \\
\hline 5. & Kemampuan Pengelolaan Keuangan & & 10 & \\
\hline 6. & Keberlanjutan Usaha & & 25 & \\
\hline & Jumlah & & 100 & \\
\hline
\end{tabular}

setelah itu diberikan skor: 1,2,3,4,5 (1: sangat buruk, 2: buruk, 3: cukup, 4: baik, 5: sangat baik). Rumus penilaiannya adalah nilai = skor $\mathrm{x}$ bobot. selanjutnya range nilainya adalah: 5-100: sangat buruk; 101-200: buruk; 201-300: cukup; 301-400: baik; 401-500: sangat baik.

\section{HASIL DAN PEMBAHASAN Sosialisasi Program}

Sosialisasi program PPK dilakukan oleh tim melalui website kampus dan media sosial agar informasi program ini diterima oleh semua mahasiswa dan alumni Universitas Muhammadiyah Palopo. Dengan sosialisasi yang merata, maka setiap mahasiswa dan alumni memiliki kesempatan yang sama untuk menjadi tenant kegiatan ini. Dari sosialisasi yang dilakukan, maka mahasiswa kemudian memasukkan proposal untuk diikutkan pada Kompetisi Bisnis Mahasiswa Muhammadiyah.

(KBMMu) sebagai bagian dari kegiatan PPK di Universitas Muhammadiyah Palopo. Proposal yang masuk menjadi salah satu indikator bahwa mahasiswa maupun alumni baik peserta PKM Kewirausahaan maupun wirausahawan yang berusaha secara mandiri memiliki motvasi untuk dibina dan didampingi menjadi wirausahawan mandiri.

\section{Seleksi Tenant}

Proses seleksi calon tenant dilakukan secara bertahap sebagai berikut: (1) sosialisasi kepada mahasiswa yang berminat di bidang kewirausahaan melalui mata kuliah SocioTechnopreneurship, (2) seleksi dilakukan secara kompetitif melalui Kompetisi Bisnis Mahasiswa Muhammadiyah (KBMMu).

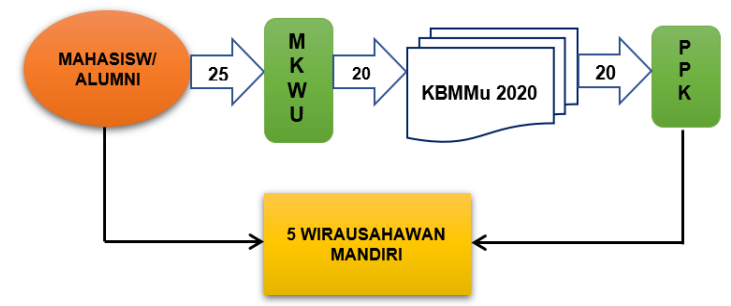

Gambar 1. Proses seleksi tenant

Pada gambar 1. nampak pola rekruitment tenant dan strategi pengisiannya kembali, dimana ditargetkan setiap tahun PPK membina 20 orang tenant, dan dari jumlah tersebut minimal 5 orang harus menjadi wirausahawan mandiri. Berdasarkan hasil evaluasi pada tahun pertama (2019), maka tahun 2020 tim pengusul memberikan syarat bagi mereka yang akan mendaftarkan diri sebagai tenant pada program PPK tahun 2020 dan 2021 yakni: (1) peserta PKM Kewirausahaan; (2) mahasiswa atau alumni yang telah menjalankan usaha baik yang telah eksis atau yang baru memulai; (3) memiliki motivasi yang dibuktikan dengan proposal kewirausahaan yang akan diikutkan pada KBMMu.

Kegiatan awal adalah dilaksanakannya Kompetisi Bisnis Mahasiswa Muhammadiyah (KBMMu) tahun 2021 dilakukan untuk mengisi tenant yang telah berwirausaha mandiri pada PPK tahun II sebanyak 6 orang. Kegiatan ini diawali dengan pengumuman, pendaftaran, penetapan finalis, presentasi, dan pengumuman pemenang, untuk mengisi tenant yang telah menjadi wirausaha mandiri sebanyak 6 orang.

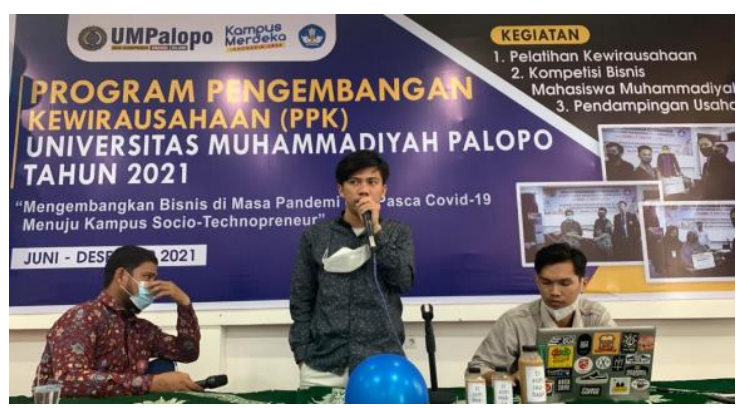

Gambar 2. Presentasi Calon Tenant

Secara umum, KBMMu adalah upaya menumbuhkan semangat kompetisi dan keuletan dalam berwirausaha, sekaligus memberikan kesempatan kepada mahasiswa wirausahawan pemula untuk melakukan Star Up dalam memulai usahanya. Selain itu, KBMMu juga sebagai instrumen agar wirausaha menjadi gerakan bersama seluruh cuvutas 
akademika. Dari hasil monitoring kegiatan ini, peserta sangat antusias mengikuti seluruh rangkaian kegiatan.

\section{Pelatihan Kewirausahaan}

Metode yang digunakan dalam pelatihan ini melalui tatap muka dengan menerapkan protokol pencegahan penularan Covid-19. Pengusul menyiapkan masker, pelindung wajah, hand sanitizer, dan mengatur jarak antar peserta. Narasumber yang terdiri dari akademisi dan praktisi menjelaskan pembentukan karakter wirausaha yang kuat, mencari ide, menjalankan usaha, membangun citra usaha, manajemen usaha, dan juga pemasaran berbasis teknologi informasi. Agar suasana pelatihan bisa lebih aktif dan hidup maka dilakukan diskusi kelompok; tenant akan dibagi dalam kelompok yang memiliki usaha serupa atau sejenis, antara lain kelompok usaha kuliner, kelompok usaha jasa, kelompok usaha perdagangan. Dalam diskusi ini tenant didampingi oleh narasumber agar tenant berani mengemukakan pendapatnya dan mendorong untuk berpikir kreatif. Pelatihan Kewirausahaan dilakukan selama 2 hari, pada tanggal 29-30 Juni 2021.

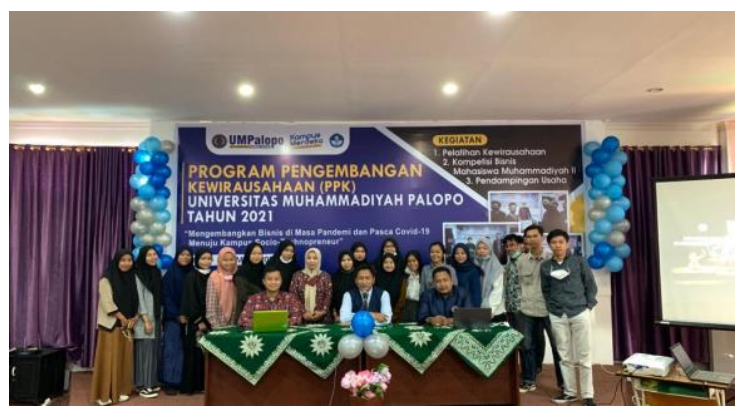

Gambar 3. Pelatihan Kewirausahaan

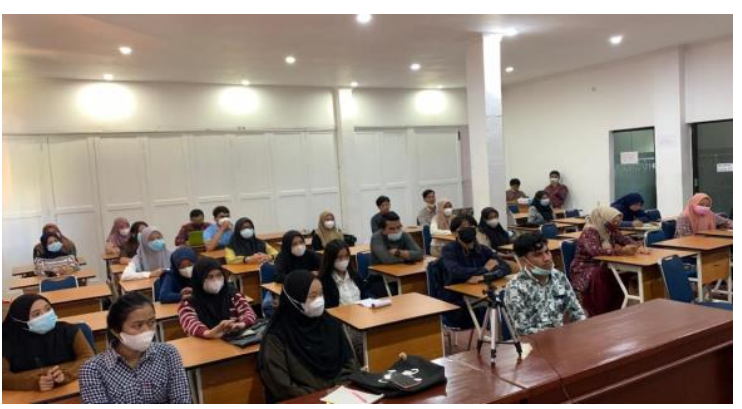

Gambar 4. Peserta Antusias Menyimak Materi

Materi yang diberikan adalah (1) caracter building wirausahawan muda; (2) kiat memulai usaha bagi pemula; (2) digital marketing; (3) manajemen keuangan; (4) membangun brand produk. Pemateri berasal dari akademisi dan praktisi serta tim pengabdi PPK tahun 2020, diantaranya (1) Asmila, S.Pd. praktisi bisnis pemilik dari Rumah Kue Palopo yang juga adalah binaan PPK tahun 2020 yang telah berhasil mengembangkan bisnisnya; (2) Goso, SE.MM. akademisi yang menekuni digital marketing; (3) Imran Ukkas SE, MM. akademisi yang menekuni manajemen produksi.

\section{Bantuan Usaha dan Teknologi}

Setelah tenant berhasil membuat business plan yang baik, maka tenant memulai merintis usaha baru. Pada awalnya tenant membiayai usaha dengan modal sendiri, namun untuk kelangsungan usaha, tenant membutuhkan tambahan dana. Sehingga tim pelaksana PPK perlu memberikan bantuan teknologi secara bertahap yang diberikan berdasarkan penilaian prospektus usaha tenant. Tim pelaksana PPK juga mengupayakan untuk mendapatkan CSR dari perusahaan; yang dapat disalurkan kepada para tenant yang membutuhkan.
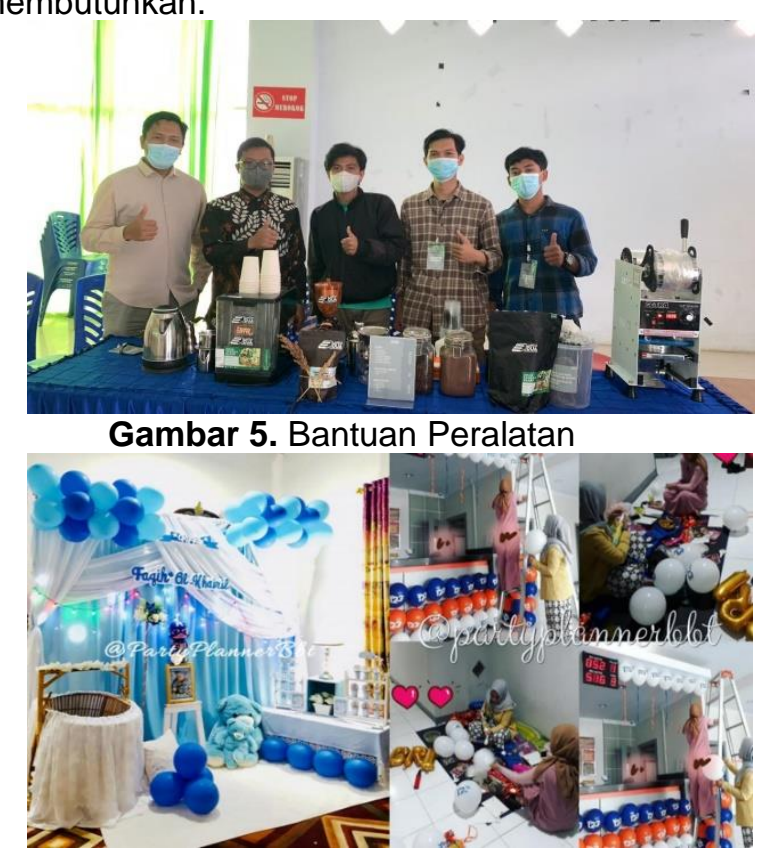

Gambar 6. Bantuan Peralatan

Bantuan peralatan diberikan kepada 6 tenant yang sudah siap berwirausaha mandiri. Dengan bantuan ini maka aspek produksi telah dapat diatasi. Dari observasi langsung oleh tim pengusul, bantuan ini menaikkan produksi baik secara kuantitas dan kualitas.

\section{Bimbingan Tenant dan Kunjungan UMKM}

Tenant dibimbing oleh tim pelaksana PPK Universitas Muhammadiyah Palopo dan mitra usaha. Tenant diberi kesempatan bila ingin konsultasi tentang usaha yang baru dirintis. Tim pelaksana PPK secara aktif terus memotivasi tenant untuk tidak mudah menyerah, apabila menghadapi masalah atau kegagalan, karena kegagalan adalah awal dari sebuah keberhasilan. Bimbingan dan pendampingan dilakukan secara efektif oleh tim pelaksana 
setiap minggu dan dilakukan evaluasi terhadap apa yang sudah dilakukan oleh tenant.

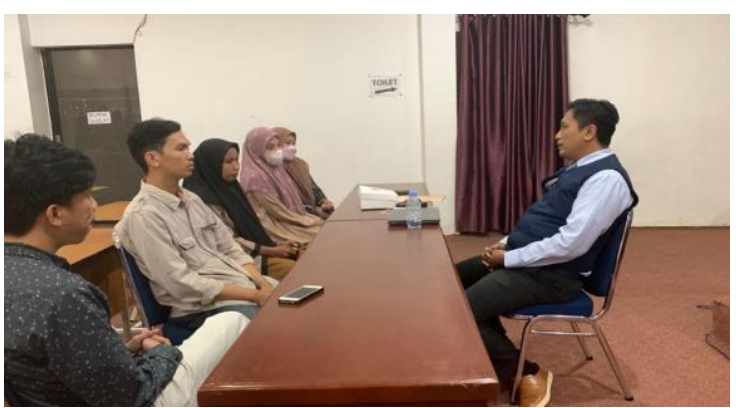

Gambar 7. Bimbingan Tenant

Kunjungan ke industri dilakukan sebagai penugasan dari seluruh rangkaian proses PPK 2021. Kunjungan dilakukan pada beberapa usaha yang berhasil. Kunjungan tahun ini dilakukan pada usaha tenant PPK tahun 2019 dan 2020 yang cukup berhasil diantaranya adalah Rumah Kue Palopo dan Sarang Palacci.

\section{Pameran Produk}

Pameran produk dilakukan pada tanggal 13-14 Agustus 2021 bertempat di Muhammadiyah Convention Centre (MCC) yang dirangkaikan dengan UMPalopo Job Fair 2021. Tim Pengusul PPK memfasilitas para tenant untuk memamerkan produknya pada kegiatan tersebut. Beberapa produk yang mengikuti pameran adalah Queen Kurma, Sambal Bajabu, Rumah Kue, Rumpun Coffe, Party Planner BBT. Kegiatan tidak hanya dihadiri oleh perusahaan, tetapi juga oleh beberapa usaha UMKM yang diberikan tempat untuk memperkenalkan dan menjual produknya.

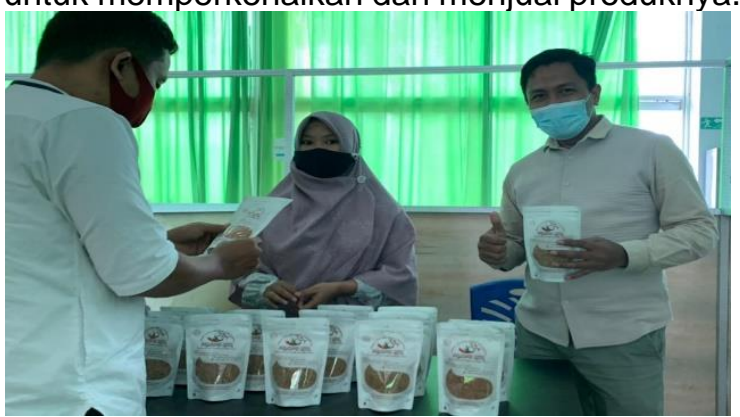

Gambar 8. Pameran Produk

Selama kurang lebih 2 hari, tanggal 1314 Agustus 2021 tenant PPK tidak hanya memamerkan produknya, tetapi juga memeroleh berbagai ilmu pengetahuan tentang dunia bisnis dari berbagai praktisi. Kegiatan ini selain memberikan omset kepada tenant, juga membentuk karakter daya saing agar percaya diri menghadapai persaingan bisnis.

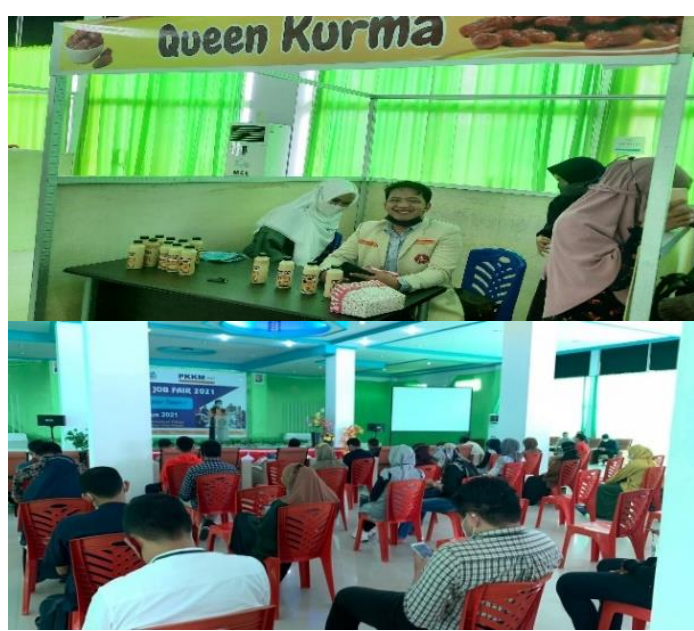

Gambar 9. Job Fair/Pameran Produk

Pada kegiatan pameran dan job fair ini diikuti oleh 10 perusahaan dari perbankan, pembiayaan, penggadaian, dan perusahaan yang sedang mencari karyawan, serta 8 produk mahasiswa yanag dibina melalui kegiatan PPK. Melalui kegiatan pameran ini, selain sebagai ajang memperkenalkan produk mahasiswa, juga terjalinnya kemitraan dan komunikasi dengan perbankan yang siap membantu mengembangkan usaha mahasiswa melalui bantuan permodalan semacam Kredit Usaha Rakyat dan skema lain.

\section{Bimbingan Tenant dan Kunjungan UMKM}

Tenant program PPK yang telah melalui proses pelatihan, pendampingan, magang, kunjungan dan konsultasi kewirausahaan setelah mahir dalam membuat bisnis plan maka tenant tersebut mulai merintis wirausaha sesuai dengan rencana usulannya. Dalam proses ini ada bantuan teknologi dan pembiayaan usaha tenant. Penilaian Kinerja Tenant dilakukan secara berkala sebanyak 3 kali, yakni Triwulan I, Triwulan II, dan Triwulan III. Hal ini dilakukan untuk memantau kemajuan dari setiap tenant dan melihat hasil dari pendampingan yang dilakukan tim pengabdi. Penilaian kinerja tenant didasarkan pada aspek sebagai berikut:

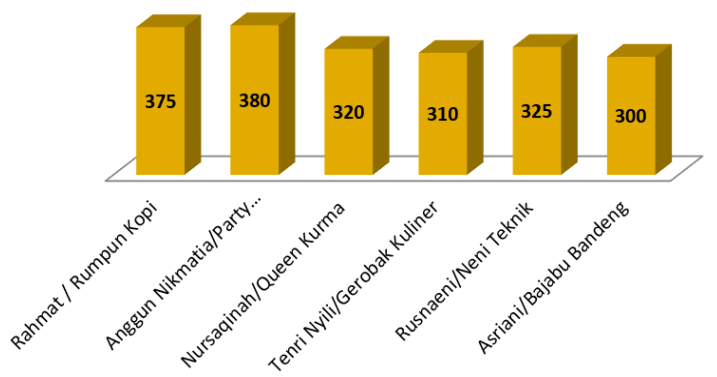

Gambar 10. Penilaian Tenant 
Pada Gambar 10 dapat dijelaskan bahwa, penilaian terhadap kinerja bisnis tenant tahun 2021 dilakukan dan hasilnya sebanyak 5 tenant dengan predikat Baik, dan 1 orang tenant dengan predikat Cukup. Dengan cara ini, akan diketahui tingkat keberhasilan pembinaan tenant.

\section{Keberhasilan PPK 2019, 2020, 2021}

Tim pengabdi terus melakukan kordinasi agar kegiatan PPK dapat berlanjut walaupun pendanaan dari kementerian sudah selesai. Saat ini Universitas Muhammadiyah Palopo memiliki Unit Inkubasi dan Pengembangan Kewirausahaan (UIPK) untuk menggerakkan potensi kewirausahaan. Saat ini, terdapat Koperasi Civitas Akademika Perguruan Tinggi Muhammadiyah, dimana P3K terlibat memberikan masukan dalam pengelolaan di dalamnya.

Berikut ini adalah tenant yang telah menjadi wirausaha baru selama tahun 2019, 2020, dan 2021.

Tabel 2. Daftar Tenant Wirausaha Baru

\begin{tabular}{clcc}
\hline No & \multicolumn{1}{c}{ Nama } & Tahun & Keterangan \\
\hline 1 & Ridwan & 2019 & Wirausaha Baru \\
2 & Amar & 2019 & Wirausaha Baru \\
3 & Asmila & 2019 & Wirausaha Baru \\
4 & Tri Putra R & 2019 & Wirausaha Baru \\
5 & Ahyar & 2019 & Wirausaha Baru \\
6 & Bahraini & 2019 & Wirausaha Baru \\
7 & Deasy & 2020 & Wirausaha Baru \\
8 & Winda M & 2020 & Wirausaha Baru \\
9 & Ghandi & 2020 & Wirausaha Baru \\
10 & Nurdiansyah & 2020 & Wirausaha Baru \\
11 & Ramdhani & 2020 & Wirausaha Baru \\
12 & Rahmat & 2021 & Wirausaha Baru \\
13 & Anggun & 2021 & Wirausaha Baru \\
14 & Nursaqinah & 2021 & Wirausaha Baru \\
15 & Tenri Nyili & 2021 & Wirausaha Baru \\
16 & Rusnaeni & 2021 & Wirausaha Baru \\
17 & Asriani & 2021 & Wirausaha Baru \\
\hline
\end{tabular}

Secara kelembagaan, Universitas Muhammadiyah Palopo memiliki tekad yang kuat memajukan lembaga ini, sebagai salah satu implementasi dari visi SocioTechnopreneur dan memiliki Entrepreneurship Priority. Untuk menjamin keberlanjutannya, tim PPK telah memprioritaskan; (1) pemberian insentif modal/peralatan, revitalisasi UIPK di Universitas Muhammadiyah Palopo untuk memperkuat inkubator bisnis, pameran, dan kunjungan perusahaan bagi mahasiswa dan alumni. Sehingga kegiatan kewirausahaan menjadi gerakan bersama secara kolektif; (2) ruang/kantor UIPK saat ini tengah direvitalisasi sebagai pusat inkubator bisnis dan galeri kegiatan penelitian dan pengabdian secara terpadu, yang dilengkapi dengan mini café agar pengunjung, mahasiswa, dan pengelola nyaman; dan (3) merencanakan produk tenant yang telah memiliki pasar cukup baik akan diupayakan oleh Tim PPK untuk dicarikan akses pengembangan dan penambahan modal ke Pemerintah Daerah atau pusat.

\section{SIMPULAN DAN SARAN}

Dari data dan analisis laporan PPK tahun 2019, 2020, dan 2021, program ini telah berhasil mengubah paradigma mahasiswa dan alumni untuk lebih berani dalam berwirausaha. Secara nyata program ini memberikan pengetahuan dan keterampilan dalam wirausaha serta bantuan berupa modal dan peralatan. Sehingga, walaupun di tengah Pandemi Covid-19 yang menghambat beberapa teknis kegiatan. Tetapi dengan komunikasi dan protokol yang ketat, kegiatan dapat berlangsung dengan aman dan didukung semua pihak, dan kegiatan para wirausaha baru dapat berlangsung dengan internalisasi teknologi pemasaran.

Saran tim PPK kepada Kemristekdikti agar kiranya dapat menyiapkan skema lain dari usaha tenant yang telah berjalan dan eksis, sehingga keberlanjutannya dapat semakin kuat. Merintis usaha sulit, tetapi mempertahankan keberlanjutannya juga tidak mudah. Jadi, selain dari usaha tenant dan tim pengusul maka diharapkan pemerintah tetap terlibat.

\section{UCAPAN TERIMAKASIH}

Tim pengabdi mengucapkan terima kasih kepada Kementerian Pendidikan, Kebudayaan, Riset dan Teknologi yang telah memberikan kepercayaan selama 3 tahun berturut-turut untuk melaksanakan PPK di Universitas Muhammadiyah Palopo. Kepada LLDIKTI Wilayah IX, Rektor Universitas Muhammadiyah Palopo, tim pengabdi, dan kepada mahasiswa dan alumni serta mitra yang telah memberikan kontribusi terhadap program PPK pada tahun 2019, 2020, dan 2021.

\section{DAFTAR RUJUKAN}

Astriani, V., \& Nooraeni, R. (2020). Determinan Pengangguran Lulusan Perguruan Tinggi $\mathrm{Di}$ Indonesia Tahun 2018. Jurnal Pendidikan Ekonomi (JUPE), 8(1), 31-37. https://doi.org/10.26740/jupe.v8n1.p3137

Etzkowitz, H. (1998). The norms of entrepreneurial science: cognitive effects of the new university-industry linkages. Research Policy, 27(8), 823-833.

Ismail, M. (2004). Konsep Sistem Informasi Manajemen. Kertas Kerja. Fakultas Ekonomi. Universitas Sumatera Utara. Medan. 
Isnaini, N. S. N., \& Lestari, R. (2015). Kecemasan pada pengangguran terdidik lulusan universitas. Universitas Muhammadiyah Surakarta, 13(1), 39-50.

Pajarianto, H., Adigoena, A. M., Ukkas, I., \& Pribadi, I. (2019). Program Pengembangan Kewirausahaan Di Perguruan Tinggi. Selaparang Jurnal Pengabdian Masyarakat Berkemajuan, 3(1), 104.

https://doi.org/10.31764/jpmb.v3i1.1211

Pakpahan, A. K. (2020). Covid-19 Dan Implikasi Bagi Usaha Mikro, Kecil, Dan Menengah. JIHI: Jurnal IImu Hubungan Internasional, 20(April), 2-6. https://doi.org/https://doi.org/10.26593/jihi .v0i0.3870.59-64

Rufi, M.', Ilyas, M., Anas, A., \& Islamiayah, R. Y. (2020). Pengembangan Kewirausahaan di Fakultas Keguruan dan IImu Pendidikan Universitas Cokroaminoto Palopo Development of Entrepreneurship in Faculty of Teacher Training and Education Cokroaminoto Polopo. Jurnal Panrita Abdi, 4(2), 225-236.

Sundoro, S. A. (2014). Entrepreneurial motivation dan persepsi terhadap hambatan pertumbuhan usaha mikro dan kecil pada sektor formal di Jawa Timur. Agora, 2(1), 14-17.

Widyani, W. M. (2013). Pentingnya Pola Kemitraan Dalam Rangka Meningkatkan Peran dan Kinerja Usaha Mikro, Kecil, dan Menengah di Jawa Timur Periode 20062011. Calyptra, 2(2), 1-12.

Yusuf, M., \& Firman, B. (2019). Evaluasi Program Pengembangan Kewirausahaan (PPK) di Institut Sains \& Teknologi Akprind Yogyakarta. Jurnal Pengabdian Masyarakat Borneo, 3(1), 31-38. 